\title{
QUY CHIẾU TR!̣ ĐO SÂU ĐỊA HÌNH ĐÁY BIỄN DỰA TRÊN MÔ HİNH TÍNH TOÁN THỦY TRIỀU VÀ CÁC MÔ HİNH MẶT BIỂN
}

\author{
NGUYẼ̃N TH!̣ HỒNG ${ }^{(1)}$, NGUYẼ̃N THANH TRANG ${ }^{(2)}$ LUUONG THANH THẠCH ${ }^{(3)}$, \\ NGUYẼ̃N AN ĐỊNH(4), TRẦN VĂN HẢI ${ }^{(5)}$, ĐỖ VĂN MONG(6) \\ (l) Truờng Đại học Hàng hải Việt Nam \\ (2) Trung tâm Hải văn, Tổng cục Biển và Hải đảo Việt Nam \\ ${ }^{(3)}$ Truờng Đại học Tài nguyên và Môi truờng Hà Nội \\ ${ }^{(4)}$ Công ty TNHH MTV Trắc địa Bản đồ \\ ${ }^{(5)}$ Xí nghiệp Trắc địa, Công ty TNHH MTV Trắc địa Bản đồ \\ (6) Đoàn Đo đạc Biên vẽ hải đồ và Nghiên cứu biển
}

\section{Tóm tắt:}

Bài báo khoa học này trình bày phưong pháp sủ dụng mô hình tính toán thủy triều MIKE21 FD để hiệu chinh thủy triều trong quy chiếu trị đo sâu địa hình đáy biển dụa trên mô hình mặt biển trung bình khu vục (MBTBKV98) và mô hình mặt biển thấp nhất khu vục (MBTNKV170) được công bố trong tài liệu [6]. Kết quả đánh giá độ chính xác hiệu độ sâu quy chiếu dựa trên mưc nước quan trắc tại trạm nghiệm triều tạm thời ven bò̀ và mô hình tính toán thủy triều khu vục biển Hải Phòng đạt $0.034 \mathrm{~m}$; hiệu độ sâu quy chiếu dưa trên mưc nước quan trắc tại trạm nghiệm triều và dựa trên mô hình MBTBKV98 kết hợp số liệu triều mô hình đạt $0.041 \mathrm{~m}$, còn hiệu độ sâu quy chiếu dựa trên mặt biển thấp nhất tại trạm nghiệm triều và dựa trên mô hình MBTNKV170 kết hợp số liẹu triều mô hình đạt $0.047 \mathrm{~m}$. Điều này cho thấy sủ dụng mô hình tính toán thủy triều MIKE21 FD để hiệu chinh thủy triều trong quy chiếu các trị đo sâu địa hình đáy biển dụa trên các mô hình mặt biển hoàn toàn đáp ưng yêu cầu thành lập bản đồ địa hình đáy biển và hải đồ ở các dãy tỷ lệ trung bình và nhỏ hơn trên vùng biển Việt Nam.

\section{1. Đặt vấn đề}

Trong công tác thành lập bản đồ địa hình đáy biển, độ sâu đo địa hình đáy biển (ĐHĐB) được quy chiếu dựa trên độ cao của mặt biển trung bình tại trạm nghiệm triều Hòn Dấu, trên cơ sở xác định độ cao quốc gia Hải Phòng 1972 (HP72) cho trạm quan trắc thủy triều (QTTT) tạm thời ven bờ của khu đo bằng phương pháp thủy chuẩn hình học hay GNSS. Trong phạm vi khu đo nhỏ với tính chất thủy triều đồng nhất, sẽ chỉ sử dụng 01 trạm QTTT. Số trạm QTTT tăng lên tùy thuộc vào tính chất triều trong toàn bộ phạm vi khu đo [5]. Quy định này nhằm hai mục đích:

- Hiệu chỉnh độ sâu đo từ mặt nước đến đáy biển do ảnh hưởng của thủy triều về mặt biển trung bình (MBTB) nhờ số liệu quan trắc mực nước tại trạm QTTT tạm thời ven bờ;

- Quy chiếu độ sâu địa hình đáy biển về mặt biển trung bình Hòn Dấu.

Tuy nhiên, “do MBTB ở các khu vực khác nhau trên vùng biển quốc gia không phải là mặt đẳng thế, tức không cùng nằm trên một mặt xác định, nên khi coi MBTB tại trạm QTTT tạm thời ven bờ trùng với MBTB tại vị trí đo sâu địa hình đáy biển ở ngoài khơi để quy chiếu kết quả đo sâu về MBTB Hòn Dấu là không có cơ sở khoa học" [3]. Mặt khác, dựa vào tính chất lan truyền thủy triều, độ cao triều tại các vị trí trong phạm vị khu đo cũng khác với độ cao triều tại trạm QTTT trong cùng một thời điểm $[6,7]$, nên hiệu chỉnh thủy triều cho các trị đo sâu dựa trên độ

Ngày nhận bài: 25/05/2020, ngày chuyển phản biện: 29/05/2020, ngày chấp nhận phản biện: 02/06/2020, ngày chấp nhận đăng: 05/06/2020 
cao triều tại trạm QTTT tạm thời ven bờ cũng không có cơ sở khoa học chắc chắn (đặc biệt đối với các trị đo sâu ở cách xa trạm QTTT).

Việc quy chiếu độ sâu ĐHĐB dựa trên mô hình MBTBKV98 và mô hình MBTNKV170 đã giải quyết được vấn đề kết nối trực tiếp độ sâu ĐHĐB tại mọi vị trí đo độ sâu vào hệ độ cao quốc gia HP72 (không dựa vào độ cao của trạm QTTT), nhưng hiệu chỉnh thủy triều trong trị đo sâu vẫn phải dựa vào số liệu đo mực nước của trạm QTTT tạm thời ven bờ [5]. Kết quả đánh giá độ chính xác hiệu trị đo giữa độ sâu quy chiếu dựa trên độ cao MBTB tại trạm QTTT tạm thời ven bờ và độ sâu quy chiếu dựa trên mô hình MDTTBKV98 đạt $0.018 \mathrm{~m}$, còn độ chính xác hiệu trị đo giữa độ sâu quy chiếu dựa trên độ cao MBTN tại trạm QTTT tạm thời ven bờ và độ sâu quy chiếu dựa trên mô hình MBTNKV170 đạt $0.038 \mathrm{~m}$.

Bài báo khoa học này giới thiệu phương pháp hiệu chỉnh thủy triều trong trị đo sâu ĐHĐB dựa vào mô hình tính toán thủy triều và quy chiếu các trị đo sâu ĐHĐB dựa trên các mô hình mặt biển theo số liệu mô hình triều.

\section{Giải quyết vấn đề}

\subsection{Giới thiệu mô hình tính toán thủy triều MIKE 21 Flow Model FM [9]}

MIKE là một bộ phần mềm bao gồm các modul: Tính toán thủy lực (MIKE 21/3 HD); tính sóng (MIKE 21 SW, NSW,PMS,EMS, BW); tính biến đổi đường bờ (LITPACK); tính biến đổi bùn cát (MIKE 21/3 ST, MT); tính tràn dầu, mô hình sinh thái (MIKE $3 \mathrm{OS}$, EcoLab) và tính lan truyền vật chất, truyền nhiệt (MIKE 3 AD), ... Phương trình cơ bản trong MIKE 21/3 là phương trình $2 / 3$ chiều áp dụng cho chất lỏng không nén được, trung bình theo Reynolds của phương trình Navier-Stokes cùng với các giả thiết Boussinesq và áp lực thủy tĩnh.

- Phương trình cơ bản:

$$
\frac{\partial \mathrm{h}}{\partial \mathrm{t}}+\frac{\partial \mathrm{h} \overline{\mathrm{u}}}{\partial \mathrm{x}}+\frac{\partial \mathrm{h} \overline{\mathrm{v}}}{\partial \mathrm{y}}=\mathrm{hS}
$$

- Phương trình liên tục:

$$
\begin{aligned}
& \frac{\partial \mathrm{h} \overline{\mathrm{u}}}{\partial \mathrm{t}}+\frac{\partial \mathrm{h} \overline{\mathrm{u}}^{2}}{\partial \mathrm{x}}+\frac{\partial \mathrm{h} \overline{\mathrm{vu}}}{\partial \mathrm{y}}=\mathrm{f} \overline{\mathrm{vh}}-\mathrm{gh} \frac{\partial \eta}{\partial \mathrm{x}}-\frac{\mathrm{gh}^{2}}{2 \rho_{0}} \frac{\partial \rho}{\partial \mathrm{x}}+\frac{\tau_{\mathrm{sx}}}{\rho}-\frac{\tau_{\mathrm{bx}}}{\rho} \\
& -\frac{1}{\rho_{0}}\left(\frac{\partial \mathrm{S}_{\mathrm{xx}}}{\partial \mathrm{x}}+\frac{\partial \mathrm{S}_{\mathrm{xy}}}{\partial \mathrm{y}}\right)+\frac{\partial}{\partial \mathrm{x}}\left(\mathrm{hT}_{\mathrm{xx}}\right)+\frac{\partial}{\partial \mathrm{y}}\left(\mathrm{hT}_{\mathrm{xy}}\right)+\mathrm{hu}_{\mathrm{s}} \mathrm{S} \\
& \frac{\partial \mathrm{h} \overline{\mathrm{v}}}{\partial \mathrm{t}}+\frac{\partial \mathrm{h} \overline{\mathrm{uv}}}{\partial \mathrm{x}}+\frac{\partial \mathrm{h} \bar{v}^{2}}{\partial \mathrm{y}}=-\mathrm{f} \overline{\mathrm{uh}}-\mathrm{gh} \frac{\partial \eta}{\partial \mathrm{y}}-\frac{\mathrm{gh}^{2}}{2 \rho_{0}} \frac{\partial \rho}{\partial \mathrm{y}}+\frac{\tau_{\mathrm{sy}}}{\rho}-\frac{\tau_{\mathrm{by}}}{\rho} \\
& -\frac{1}{\rho_{0}}\left(\frac{\partial \mathrm{S}_{\mathrm{yx}}}{\partial \mathrm{x}}+\frac{\partial \mathrm{S}_{\mathrm{yy}}}{\partial \mathrm{y}}\right)+\frac{\partial}{\partial \mathrm{x}}\left(\mathrm{hT}_{\mathrm{xy}}\right)+\frac{\partial}{\partial \mathrm{y}}\left(\mathrm{hT}_{\mathrm{yy}}\right)+\mathrm{hv}_{\mathrm{s}} \mathrm{S}
\end{aligned}
$$

Trong đó các ký hiệu có gạch ngang trên đầu biểu thị các thành phần được lấy trung bình theo độ sâu cột nước $(h=\eta+d)$ với các ký hiệu: $\mathrm{t}$ là thời gian; $h$ là độ sâu; $g$ là gia tốc trọng trường; $\mathrm{f}$ là tham số lực coriolit; $\mathrm{s}$ là lưu lượng; $\mathrm{p}_{0}$ là mật độ nước tham chiếu; $p$ là mật độ nước; $\eta$ là giao động mực nước; $\mathrm{p}_{\mathrm{a}}$ là áp suất không hí; $\mathrm{x}$, $\mathrm{y}$ là toạ độ vuông góc Descartes; $\mathrm{u}, \mathrm{v}$ là vận tốc theo các hướng trục tọa độ; $\mathrm{S}_{\mathrm{xx}}, \mathrm{S}_{\mathrm{xy}}, \mathrm{S}_{\mathrm{yx}}, \mathrm{S}_{\mathrm{yy}}$ là các thành phần ứng suất; 酸" ứng suất đáy; $\mathrm{u}_{\mathrm{s}}, \mathrm{v}_{\mathrm{s}}$ là vận tốc tại các nhập lưu; $\mathrm{T}_{\mathrm{xx}}, \mathrm{T}_{\mathrm{xy}}, \mathrm{T}_{\mathrm{yx}}, \mathrm{T}_{\mathrm{yy}}$ là các thành phần ứng lực nhập lưu theo phương ngang.

MIKE 21 Flow Model FM là mô hình để tính toán các bài toán thủy lực áp dụng cho khu vực cửa sông, vịnh và biển. Mô hình bao gồm các modul: Modul thủy lực (tính toán mực nước và dòng chảy 2 chiều); modul vận chuyển bùn cát; modul lan truyền dầu/sinh thái; modul vận chuyển bùn cát và modul theo dõi đường đi hạt. Trong các modul của MIKE 21 Flow Model FM thì MIKE 21 EM là modul tính toán thủy lực cơ bản của toàn bộ hệ thống MIKE, cung cấp các tính toán thủy lực cho các modul khác.

Mô hình Mike 21 FM tính toán các quá trình thủy lực 2D. Modul dòng chảy được phát triển bởi phương pháp lưới phần tử hữu hạn dựa trên nghiệm số của hệ các phương trình NavierStokes cho chất lỏng không nén được 2 hoặc 3 chiều, kết hợp với giả thiết Boussinesq và giả thiết về áp suất thuỷ tĩnh. Do đó, modul bao gồm các phương trình: phương trình liên tục, động 
lượng, nhiệt độ, độ muối, mật độ và được khép kín bởi sơ đồ khép kín rối.

Việc rời rạc hoá không gian của các phương trình cơ bản được thực hiện bằng việc sử dụng phương pháp thể tích hữu hạn trung tâm. Miền không gian được rời rạc hoá bằng việc chia nhỏ miền liên tục thành các ô lưới/phần tử không trùng nhau. Theo phương ngang thì lưới phi cấu trúc được sử dụng còn theo phương thẳng đứng trong trường hợp 3 chiều thì sử dụng lưới có cấu trúc. Trong trường hợp hai chiều các phần tử có thể là phần tử tam giác hoặc tứ giác. Đối với trường hợp ba chiều các phần tử có thể là hình lăng trụ tam giác hoặc lăng trụ tứ giác với các phần tử trên mặt có dạng tam giác hoặc tứ giác.

2.2. Qui chiếu trị đo sâu địa hình đáy biển dụa trên mô hình tính toán thủy triều MIKE21 FM

a. Quy chiếu trị đo sâu ĐHĐB dưa trên MBTB và mô hình MBTBKH98 theo số liệu mô hình triều

- Độ cao mực nước tính từ mô hình triều MIKE21 FM tại vị trí đo điểm độ sâu được quy chiếu về MBTB dựa trên lưới tính phủ trùm phạm vi khu vực đo độ sâu ĐHĐB (xem mục 3 ở dưới đây). Độ sâu ĐHĐB dựa trên MBTB theo số liệu mực nước tính từ mô hình triều được quy chiếu theo công thức (hình 1):

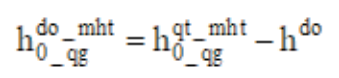

trong đó:

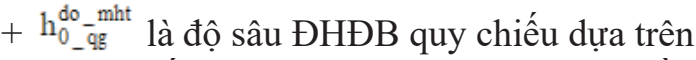
MBTB theo số liệu mực nước của mô hình triều MIKE21;

$+\mathrm{h}_{0-\mathrm{qg}}^{\mathrm{qt} \text { mat }}$ là độ cao mực nước tính theo mô hình triều MIKE21 FM và được quy chiếu dựa trên MBTB;

+ $\mathrm{h}^{\mathrm{do}}$ là độ sâu đo từ mặt nước đến đáy biển.

\section{(Xem hinh 1)}

- Độ sâu ĐHĐB quy chiếu dựa trên mô hình MBTBKV98 theo số liệu mực nước của mô hình triều MIKE21 được tính bởi công thức (xem hình 2):

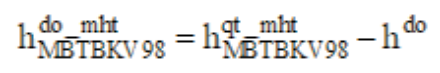

trong đó:

$+\mathrm{h}_{\mathrm{M} B \text { TBKKV } 98}^{\text {do mht }}$ là độ sâu ĐHĐB quy chiếu dựa trên mô hình MDTTBKV98 theo số liệu mực nước của mô hình triều MIKE21;

$+\mathrm{h}_{\text {MBTBKVy }}^{\text {qt mht }}$ là độ cao mực nước tính theo mô hình triều MIKE21 FM và được quy chiếu dựa trên mô hình MBTBKV98;

$+\mathrm{h}^{\mathrm{do}}$ là độ sâu đo từ mặt nước đến đáy biển.

\section{(Xem hinh 2)}

b. Quy chiếu trị đo độ sâu ĐHĐB dựa trên MBTN và mô hình MBTNKH170 theo số liệu mưc nước của mô hình triều

- Độ cao mực nước dựa trên MBTN tính từ mô hình triều MIKE21 FM tại vị trí đo điểm độ sâu được quy chiếu theo độ cao mực nước tính từ mô hình triều MIKE21 FM được quy chiếu về $M B T B$ và độ chênh giữa $M B T B$ và $M B T N$ $(\mathrm{A} 0-\pi 0)$ Độ sâu ĐHĐB dựa trên MBTN theo số liệu mực nước tính từ mô hình triều được quy chiếu theo công thức (hình 1):

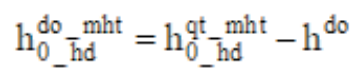

trong đó:

$+\mathrm{h}_{0}^{\text {do }}$ hnd mht là độ sâu ĐHĐB quy chiếu dựa trên MBTN theo số liệu mực nước của mô hình triều MIKE21;

$+\mathrm{h}_{0}^{\mathrm{qt}}$-mint là độ cao mực nước tính theo mô hình triêu MIKE21 FM tại vị trí đo điểm độ sâu được quy chiếu theo độ cao mực nước tính từ mô hình triều MIKE21 FM được quy chiếu về $M B T B$ và độ chênh giữa $M B T B$ và $M B T N$ $(\mathrm{A} 0-\pi 0)$ được tính theo công thức

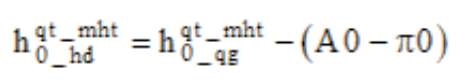

$+\mathrm{h}^{\text {do }}$ là độ sâu đo từ mặt nước đến đáy biển.

- Độ sâu ĐHĐB quy chiếu dựa trên mô hình 


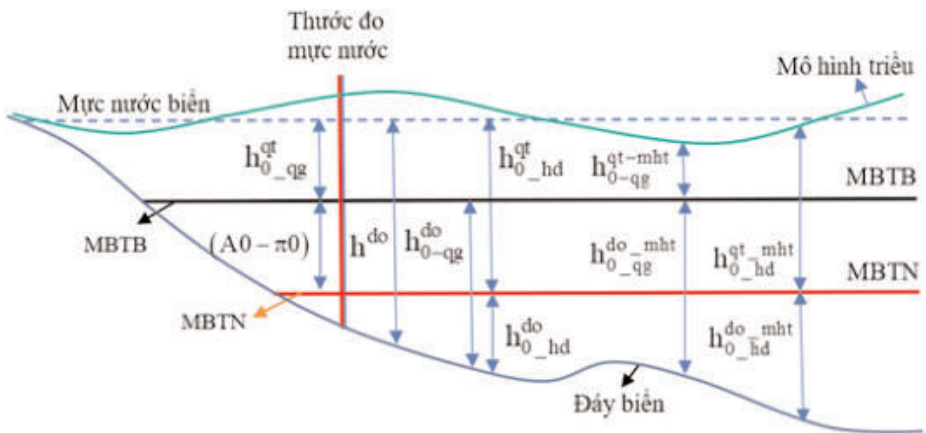

Hình 1: Quy chiếu trị đo mưc nước và trị đo sâu ĐHĐB dụa trên độ cao MBTB tại trạm QTTT và độ cao MBTB tại vị trí các điểm đo độ sâu theo số liệu mục nước của mô hình MIKE 21 FM

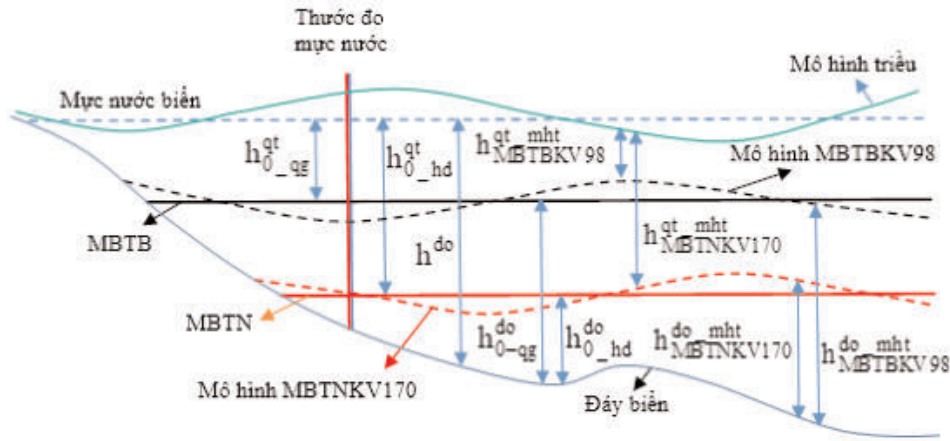

Hình 2: Quy chiếu trị đo mưc nước và trị đo sâu ĐHĐB dựa trên các mô hình MBTBKV98, MBTNKV170 theo số liệu của mô hình MIKE 21 FM

MBTNKV170 theo số liệu mực nước của mô hình triều MIKE21 được tính bởi công thức (xem hình 2):

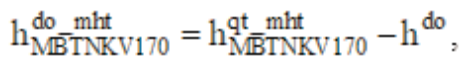

trong đó:

$+\mathrm{h}_{\mathrm{MB} \text { BNKV170 }}^{\text {do mht }}$ là độ sâu ĐHĐB quy chiếu dựa trên mô hình MDTTNKV170 theo số liệu mực nước của mô hình triều MIKE21;

$+\mathrm{h}_{\text {MBRTKV170 }}^{\text {qt } \text { mht }}$ là độ cao mực nước tính theo mô hình triều MIKE21 FM và được quy chiếu dựa trên mô hình MBTNKV170;

$+\mathrm{h}^{\text {do }}$ là độ sâu đo từ mặt nước đến đáy biển.

Độ chính xác hiệu độ sâu quy chiếu dựa trên MBTB tại trạm nghiệm triều và dựa trên các mô hình mặt biển được đánh giá theo phương pháp hiệu chỉnh toán học các trị đo kép độc lập cùng độ chính xác.

\section{Tính toán thực nghiệm}

a. Số liệu phục vụ tính toán thục nghiệm

Để đánh giá chất lượng của mô hình tính toán thủy triều phục vụ hiệu chỉnh mực nước thủy triều trong đo sâu ĐHĐB, chúng tôi tiếp tục sử dụng số liệu đo luồng hàng hải Lạch Huyện khu vực biển Hải Phòng của Bộ môn An toàn đường thủy, Khoa Công trình, Trường Đại học Hàng hải Việt Nam đo trong các ngày 21, 22/12/2019 [5].

b. Xây dựng bài toán tính thủy triều tại khu vực biển Hải Phòng (theo phuoong pháp của Trung tâm Hải văn, Tổng cục Biển và Hải đảo Việt Nam)

- Xây dựng lưới tính và các điều kiện biên

Lưới tính được xây dựng cho khu vực luồng Hải Phòng là lưới tam giác có độ phân giải cao nhất là 20 mét và thưa dần ra ngoài khơi khoảng 300 mét. Lưới tính bao gồm 4 biên lỏng, trong 
đó có 2 biên biển (biên khu vực cửa biển từ đảo Cát Bà sang), hai biên sông tại Trạm thủy văn Cửa Cấm (trên Sông Cấm) và trạm thủy văn Do Nghi (trên sông Đá Bạch).

+ Mực nước tại biên biển là số liệu dự tính thủy triều được quy về độ cao quốc gia theo số liệu tại trạm nghiệm triều Hòn Dấu;

+ Mực nước tại trạm Do Nghi và Cửa Cấm là số liệu mực nước đã quy về độ cao nhà nước tại 2 trạm thủy văn Do Nghi và Cửa Cấm;

+ Trước khi mô hình đưa vào dự tính thủy triều tại các thời điểm đo sâu, mô hình được hiệu chỉnh và kiểm định kỹ lưỡng dựa trên số liệu quan trắc mực nước thực tế tại khu vực Hải Phòng. Kết quả kiểm định và hiệu chỉnh mô hình đều cho độ chính xác của mô hình đạt loại tốt theo chỉ tiêu Nash - Sutcliffe [8].

- Tính toán mực nước trung bình nhiều năm, mực nước thấp nhất nhiều năm

Để tính toán mực nước trung bình nhiều năm và mực nước thấp nhất nhiều năm, chúng tôi đã tính toán mực nước trên toàn bộ lưới tính với thời gian 20 năm từ năm 1999 đến 2018 với biên sông là số liệu mực nước thực đo tại trạm Do Nghi và Cửa Cấm, biên biển là mực nước thủy triều được phân tích từ bộ hằng số điều hòa được tích hợp trong bộ phần mềm Mike đã quy về cao độ nhà nước theo số liệu của trạm nghiệm triều Hòn Dấu.

\section{c. Tính toán thực nghiệm}

Tiến hành tính toán thực nghiệm theo phương pháp đã được triển khai trong mục 2.3 để quy chiếu trị quan trắc mực nước và trị đo sâu ĐHĐB cho các trường hợp sau:

- Quy chiếu dựa trên độ cao MBTB theo số liệu quan trắc mực nước tại trạm QTTT tạm thời ven bờ và dựa trên MBTB tại vị trí các điểm đo độ sâu ĐHĐB theo số liệu của mô hình triều. Kết quả quy chiếu trị quan trắc mực nước và trị đo sâu ĐHĐB trong trường hợp này được trình bày trong bảng 1 .

- Quy chiếu dựa trên MBTB theo số liệu quan trắc mực nước tại trạm QTTT tạm thời ven bờ và dựa trên mô hình MBTBKV98, mô hình MBTNKV170 theo số liệu của mô hình triều. Kết quả quy chiếu trị quan trắc mực nước và trị đo sâu $\mathrm{ĐHĐB} \mathrm{trong} \mathrm{trường} \mathrm{hợp} \mathrm{này} \mathrm{được} \mathrm{trình}$ bày trong bảng 2 .

\section{d. Đánh giá độ chính xác}

- Đánh giá độ chính xác giữa hai dãy độ sâu quy chiếu dựa trên độ cao MBTB theo số liệu quan trắc mực nước tại trạm QTTT tạm thời ven bờ và dựa trên MBTB tại vị trí các điểm đo độ sâu ĐHĐB theo số liệu của mô hình triều

Xem độ sâu quy chiếu dựa trên độ cao MBTB theo số liệu quan trắc mực nước tại trạm QTTT tạm thời ven bờ và dựa trên $\mathrm{MBTB}$ tại vị trí các điểm đo độ sâu ĐHĐB theo số liệu của mô hình triều là hai dãy trị đo độc lập cùng độ chính xác và đánh giá độ chính xác.

Kết quả kiểm tra sai số hệ thống

$\mathrm{A}=\sum_{\mathrm{i}=1}^{11140} \mathrm{~d}_{\mathrm{i}}^{\mathrm{tb}}=1022.44 \mathrm{~m}, \mathrm{~B}=\sum_{\mathrm{i}=1}^{11140}\left|\mathrm{~d}_{\mathrm{i}}^{\mathrm{tb}}\right|=1022.44 \mathrm{~m}$.

Do $|A|=1022.44>0.25 . B=255.61$, nên trong hai dãy trị đo trên có chứa sai sô hệ thống. Tiến hành khử sai số hệ thống theo phương pháp Besel:

+ Tính số hiệu chỉnh $\delta^{\text {tb }}$ theo công thức:

$$
\delta^{\text {tb }}=\frac{\left[\mathrm{d}^{\mathrm{tb}}\right]}{\mathrm{n}}=0.09 \mathrm{~m}
$$

+ Khử sai số hệ thống khỏi hiệu $\mathrm{d}_{\mathrm{i}}$ theo công thức: $\quad \varepsilon_{\mathrm{i}}^{\mathrm{tb}}=\mathrm{d}_{\mathrm{i}}^{\mathrm{tb}}-\delta^{\mathrm{tb}}$

Kết quả kiểm tra sau khi khử sai số hệ thống, trong hiệu $\varepsilon_{i}^{\text {tb }}$ không còn chứa sai số hệ thống.

+ Tính sai số trung phương theo công thức:

$$
\mathrm{m}^{\mathrm{tb}}= \pm \sqrt{\frac{[\varepsilon \varepsilon]}{2(\mathrm{n}-1)}}= \pm \sqrt{\frac{25.913}{2.11139}}= \pm 0.034 \mathrm{~m}
$$

- Đánh giá độ chính xác giữa các dãy độ sâu quy chiếu dựa trên độ cao MBTN theo số liệu quan trắc mực nước tại trạm QTTT tạm thời ven bờ và dựa trên MBTN tại vị trí các điểm đo độ sâu ĐHĐB theo số liệu của mô hình triều. 
Bảng 1: Quy chiếu trị quan trắc mục nước và trị đo sâu $Đ H Đ B$ dụa trên MBTB theo số liệu quan trắc mục nước tại trạm QTTT tạm thời ven bờ và dụa trên MBTB tại vị trí các điểm đo độ sâu theo số liệu của mô hình tính toán thủy triều MIKE 21 FM

\begin{tabular}{|c|c|c|c|c|c|c|c|c|c|c|c|c|c|c|}
\hline Stt & $\mathrm{X}(\mathrm{m})$ & $\mathrm{Y}(\mathrm{m})$ & Time & $\begin{array}{l}\text { Độ sâu } \\
\text { đo } \\
(\mathrm{m})\end{array}$ & $\begin{array}{c}\text { Mực nước } \\
\text { quan trăc } \\
\text { quy chiêu } \\
\text { dựa trên } \\
\text { MBTB tại } \\
\text { TNT } \\
\text { (m) }\end{array}$ & \begin{tabular}{|c|} 
Mực nước \\
quan trắc \\
quy chiêu \\
dựa trên \\
MBTN tại \\
TNT \\
(m)
\end{tabular} & $\begin{array}{c}\text { Độ sâu } \\
\text { quy chiểu } \\
\text { dựa trên } \\
\text { MBTB } \\
\text { tại TNT } \\
\text { (m) }\end{array}$ & \begin{tabular}{|c|} 
Độ sâu \\
quy chiểu \\
dựa trên \\
MBTN \\
tại TNT \\
(m)
\end{tabular} & \begin{tabular}{|c|} 
Mực nước \\
quy chiêu \\
dựa trên \\
MBTB \\
theo số \\
liệu mồ \\
hinh triểu \\
(m)
\end{tabular} & $\begin{array}{c}\text { Mực nước } \\
\text { quy chiếu } \\
\text { dựa trên } \\
\text { MBTN } \\
\text { theo sồ } \\
\text { liệu mồ } \\
\text { hinh triểu } \\
\text { (m) }\end{array}$ & $\begin{array}{c}\text { Độ sâu quy } \\
\text { chiêu dựa } \\
\text { trên MBTB } \\
\text { theo sồ liệu } \\
\text { mô hinh } \\
\text { triểu }(\mathrm{m})\end{array}$ & $\begin{array}{l}\text { Độ sâu quy } \\
\text { chiêu dựa } \\
\text { trên MBTN } \\
\text { theo sô liệu } \\
\text { mô hinh } \\
\text { triểu (m) }\end{array}$ & $\begin{array}{c}\text { Độ chênh } \\
\mathrm{d}^{\mathrm{IB}}= \\
(8)-(14)\end{array}$ & $\begin{array}{c}\text { Độ chênh } \\
\delta^{\mathrm{TN}}= \\
(9)-(15)\end{array}$ \\
\hline (1) & (2) & (3) & (4) & (5) & (6) & (7) & (8) & (9) & (12) & (13) & (14) & (15) & (16) & (17) \\
\hline 1 & 2293621 & 626316 & $7: 33: 42$ & 11.34 & 0.71 & 2.84 & -10.63 & -8.50 & 0.61 & 2.74 & -10.73 & -8.60 & 0.10 & 0.10 \\
\hline 2 & 2293615 & 626309 & $7: 33: 47$ & 11.74 & 0.71 & 2.84 & -11.03 & -8.90 & 0.61 & 2.74 & -11.13 & -9.00 & 0.10 & 0.10 \\
\hline 3 & 2293609 & 626301 & $7: 33: 48$ & 12.04 & 0.71 & 2.84 & -11.33 & -9.20 & 0.61 & 2.74 & -11.43 & -9.30 & 0.10 & 0.10 \\
\hline 4 & 2293602 & 626293 & $7: 33: 51$ & 12.04 & 0.71 & 2.84 & -11.33 & -9.20 & 0.61 & 2.74 & -11.43 & -9.30 & 0.10 & 0.10 \\
\hline 5 & 2293596 & 626285 & $7: 33: 54$ & 12.04 & 0.71 & 2.84 & -11.33 & -9.20 & 0.61 & 2.74 & -11.43 & -9.30 & 0.10 & 0.10 \\
\hline 6 & 2293590 & 626277 & $7: 33: 57$ & 12.94 & 0.71 & 2.84 & -12.23 & -10.10 & 0.61 & 2.74 & -12.33 & -10.20 & 0.10 & 0.10 \\
\hline 7 & 2293585 & 626269 & $7: 34: 00$ & 14.54 & 0.71 & 2.84 & -13.83 & -11.70 & 0.61 & 2.74 & -13.93 & -11.80 & 0.10 & 0.10 \\
\hline 8 & 2293579 & 626260 & $7: 34: 03$ & 14.14 & 0.71 & 2.84 & -13.43 & -11.30 & 0.61 & 2.74 & -13.53 & -11.40 & 0.10 & 0.10 \\
\hline 9 & 2293574 & 626252 & $7: 34: 06$ & 14.84 & 0.71 & 2.84 & -14.13 & -12.00 & 0.61 & 2.74 & -14.23 & -12.10 & 0.10 & 0.10 \\
\hline & & & & & & & & & & & & & & \\
\hline 3401 & 2288963 & 629601 & $10: 23: 42$ & 17.43 & 0.94 & 3.07 & -16.49 & -14.36 & 0.90 & 3.03 & -16.63 & -14.50 & 0.04 & 0.04 \\
\hline 3402 & 2288969 & 629609 & $10: 23: 45$ & 17.33 & 0.94 & 3.07 & -16.39 & -14.26 & 0.90 & 3.03 & -16.73 & -14.60 & 0.04 & 0.04 \\
\hline 3403 & 2288975 & 629617 & $10: 23: 48$ & 17.43 & 0.94 & 3.07 & -16.49 & -14.36 & 0.90 & 3.03 & -16.43 & -14.30 & 0.04 & 0.04 \\
\hline 3404 & 2288980 & 629625 & 10:23:51 & 17.43 & 0.94 & 3.07 & -16.49 & -14.36 & 0.90 & 3.03 & -16.63 & -14.50 & 0.04 & 0.04 \\
\hline 3405 & 2288986 & 629634 & $10: 23: 54$ & 17.53 & 0.94 & 3.07 & -16.59 & -14.46 & 0.90 & 3.03 & -16.53 & -14.40 & 0.04 & 0.04 \\
\hline & & & & & & & & & & & & & & \\
\hline 6872 & 2296967 & 623854 & $13: 30: 23$ & 7.68 & 0.67 & 2.80 & -7.01 & -4.88 & 0.56 & 2.69 & -10.15 & -8.02 & 0.11 & 0.11 \\
\hline 6873 & 2296973 & 623863 & $13: 30: 26$ & 7.49 & 0.67 & 2.80 & -6.82 & -4.69 & 0.56 & 2.69 & -9.66 & -7.53 & 0.11 & 0.11 \\
\hline 6874 & 2296978 & 623871 & $13: 30: 29$ & 6.90 & 0.67 & 2.80 & -6.23 & -4.10 & 0.56 & 2.69 & -8.91 & -6.78 & 0.11 & 0.11 \\
\hline 6875 & 2296984 & 623879 & $13: 30: 32$ & 6.03 & 0.67 & 2.80 & -5.36 & -3.23 & 0.56 & 2.69 & -8.07 & -5.94 & 0.11 & 0.11 \\
\hline 6876 & 2296989 & 623888 & $13: 30: 35$ & 5.67 & 0.67 & 2.80 & -5.00 & -2.87 & 0.56 & 2.69 & -7.12 & -4.99 & 0.11 & 0.11 \\
\hline 6877 & 2296995 & 623896 & $13: 30: 38$ & 5.58 & 0.67 & 2.80 & -4.91 & -2.78 & 0.56 & 2.69 & -6.93 & -4.80 & 0.11 & 0.11 \\
\hline 6878 & 2297000 & 623907 & 13:30:41 & 5.39 & 0.67 & 2.80 & -4.72 & -2.59 & 0.56 & 2.69 & -6.34 & -4.21 & 0.11 & 0.11 \\
\hline
\end{tabular}

\begin{tabular}{|c|c|c|c|c|c|c|c|c|c|c|c|c|c|c|}
\hline \multicolumn{15}{|c|}{ Ngày 22/12/2019 } \\
\hline 6879 & 2303182 & 619275 & $8: 06: 35$ & 9.45 & 0.55 & 2.68 & -8.90 & -6.77 & 0.56 & 2.69 & -5.47 & -3.34 & 0.11 & 0.11 \\
\hline 6880 & 2303345 & 619080 & $8: 06: 53$ & 7.02 & 0.55 & 2.68 & -6.47 & -4.34 & 0.56 & 2.69 & -5.11 & -2.98 & 0.11 & 0.11 \\
\hline 6881 & 2303336 & 619076 & $8: 07: 12$ & 7.51 & 0.55 & 2.68 & -6.96 & -4.83 & 0.56 & 2.69 & -5.02 & -2.89 & 0.11 & 0.11 \\
\hline 6882 & 2303326 & 619072 & $8: 07: 30$ & 7.44 & 0.55 & 2.68 & -6.89 & -4.76 & 0.56 & 2.69 & -4.83 & -2.70 & 0.11 & 0.11 \\
\hline 6883 & 2303317 & 619068 & $8: 07: 48$ & 7.86 & 0.55 & 2.68 & -7.31 & -5.18 & 0.47 & 2.60 & -8.98 & -6.85 & 0.08 & 0.08 \\
\hline 6884 & 2303308 & 619064 & 8:07:54 & 8.75 & 0.55 & 2.68 & -8.20 & -6.07 & 0.47 & 2.60 & -6.55 & -4.42 & 0.08 & 0.08 \\
\hline 6885 & 2303299 & 619060 & $8: 08: 17$ & 9.93 & 0.55 & 2.68 & -9.38 & -7.25 & 0.48 & 2.61 & -7.03 & -4.90 & 0.07 & 0.07 \\
\hline 6886 & 2303290 & 619055 & $8: 08: 21$ & 10.36 & 0.55 & 2.68 & -9.81 & -7.68 & 0.48 & 2.61 & -6.96 & -4.83 & 0.07 & 0.07 \\
\hline \multirow[t]{2}{*}{6887} & 2303281 & 619051 & $8: 08: 42$ & 10.70 & 0.55 & 2.68 & -10.15 & -8.02 & 0.48 & 2.61 & -7.38 & -5.25 & 0.07 & 0.07 \\
\hline & & & & & & & & & & & & & & \\
\hline 9001 & 2300848 & 620948 & $15: 31: 03$ & 16.02 & 0.25 & 2.38 & -15.77 & -13.64 & 0.10 & 2.23 & -16.23 & -14.10 & 0.15 & 0.15 \\
\hline 9002 & 2300842 & 620940 & 15:31:06 & 15.82 & 0.25 & 2.38 & -15.57 & -13.44 & 0.10 & 2.23 & -16.23 & -14.10 & 0.15 & 0.15 \\
\hline 9003 & 2300837 & 620932 & 15:31:09 & 15.72 & 0.25 & 2.38 & -15.47 & -13.34 & 0.10 & 2.23 & -16.03 & -13.90 & 0.15 & 0.15 \\
\hline 9004 & 2300831 & 620924 & 15:31:11 & 14.42 & 0.25 & 2.38 & -14.17 & -12.04 & 0.10 & 2.23 & -15.53 & -13.40 & 0.15 & 0.15 \\
\hline \multirow[t]{2}{*}{9005} & 2300825 & 620915 & $15: 31: 15$ & 15.52 & 0.25 & 2.38 & -15.27 & -13.14 & 0.09 & 2.22 & -15.93 & -13.80 & 0.16 & 0.16 \\
\hline & & & & & & 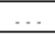 & & & $\ldots$ & $\ldots$ & & & $\ldots$ & 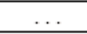 \\
\hline 11133 & 2293643 & 626250 & 17:17:39 & 12.11 & 0.08 & 2.21 & -12.03 & -9.90 & -0.12 & 2.01 & -12.23 & -10.10 & 0.20 & 0.20 \\
\hline 11134 & 2293649 & 626258 & $17: 17: 41$ & 11.41 & 0.08 & 2.21 & -11.33 & -9.20 & -0.12 & 2.01 & -11.53 & -9.40 & 0.20 & 0.20 \\
\hline 11135 & 2293655 & 626266 & $17: 17: 45$ & 11.11 & 0.08 & 2.21 & -11.03 & -8.90 & -0.12 & 2.01 & -11.23 & -9.10 & 0.20 & 0.20 \\
\hline 11136 & 2293662 & 626274 & $17: 17: 48$ & 11.01 & 0.08 & 2.21 & -10.93 & -8.80 & -0.12 & 2.01 & -11.13 & -9.00 & 0.20 & 0.20 \\
\hline 11137 & 2293668 & 626281 & $17: 17: 51$ & 11.01 & 0.08 & 2.21 & -10.93 & -8.80 & -0.12 & 2.01 & -11.13 & -9.00 & 0.20 & 0.20 \\
\hline 11138 & 2293675 & 626289 & $17: 17: 53$ & 10.51 & 0.08 & 2.21 & -10.43 & -8.30 & -0.12 & 2.01 & -10.63 & -8.50 & 0.20 & 0.20 \\
\hline 11139 & 2293680 & 626298 & $17: 17: 57$ & 9.71 & 0.08 & 2.21 & \begin{tabular}{|l|}
-9.63 \\
\end{tabular} & -7.50 & -0.12 & 2.01 & -9.83 & -7.70 & 0.20 & 0.20 \\
\hline \multirow[t]{3}{*}{11140} & 2293685 & \begin{tabular}{|l|l|}
626306 \\
\end{tabular} & $17: 18: 00$ & 6.81 & 0.08 & 2.21 & -6.73 & -4.60 & -0.12 & 2.01 & -6.93 & -4.80 & 0.20 & 0.20 \\
\hline & & & & & & & & & & & & $\Sigma=$ & 1022.44 & 1022.44 \\
\hline & & & & & & & & & & & & $\mathrm{m}=$ & 0.034 & 0.034 \\
\hline
\end{tabular}


Bảng 2: Quy chiếu trị quan trắc mưc nước và trị đo sâu ĐHĐB dựa trên MBTB theo số liệu quan trắc mực nước tại trạm QTTT tạm thời ven bờ và các mô hìn MBTBKV98, MBTNKV170 theo số liệu của mô hìn tính toán thủy triều MIKE 21 FM

\begin{tabular}{|c|c|c|c|c|c|c|c|c|c|c|c|c|c|c|c|c|}
\hline Stt & $\mathrm{X}(\mathrm{m})$ & $\mathrm{Y}(\mathrm{m})$ & Time & $\begin{array}{c}\text { Độ sâu } \\
\text { đo } \\
(\mathrm{m})\end{array}$ & $\begin{array}{c}\text { Mực nước cóc } \\
\text { quan trăc } \\
\text { quy chiêu } \\
\text { dự trên } \\
\text { MBiB tai } \\
\text { tramm } \\
\text { QTTT } \\
\text { (m) }\end{array}$ & $\begin{array}{c}\text { Mực nước } \\
\text { quan trắc } \\
\text { quy chiêu } \\
\text { dự tên } \\
\text { MBiTN tại } \\
\text { tram } \\
\text { QTTT } \\
\text { (m) }\end{array}$ & $\begin{array}{c}\text { Đồ sâu } \\
\text { quy chiêu } \\
\text { dựa trên } \\
\text { MBTB } \\
\text { tại tram } \\
\text { QTTT } \\
\text { (m) }\end{array}$ & \begin{tabular}{|c} 
Độ sâu \\
quy chiêu \\
dựa trên \\
MBTN \\
tại trạm \\
QTTT \\
(m)
\end{tabular} & $\begin{array}{c}\text { Độ cao } \\
\text { mô hinh } \\
\text { MBTBK } \\
\text { V 98 } \\
\text { (m) }\end{array}$ & $\begin{array}{c}\text { Độ cao } \\
\text { mô hinh } \\
\text { MBTNK } \\
\text { V170 } \\
\text { (m) }\end{array}$ & $\begin{array}{c}\text { Mực nước } \\
\text { mô hinh } \\
\text { triêu quy } \\
\text { chiêu dựa } \\
\text { trên mố } \\
\text { hinh } \\
\text { MBTBKV } \\
98(\mathrm{~m})\end{array}$ & $\begin{array}{c}\text { Mực nước } \\
\text { mô hinh } \\
\text { triêu quy } \\
\text { chiêuu dựa } \\
\text { trên mồ } \\
\text { hinh } \\
\text { MBTNKV } \\
170(\mathrm{~m})\end{array}$ & 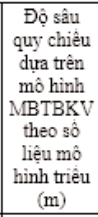 & 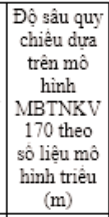 & $\begin{array}{c}\text { Độ } \\
\text { chênh } \\
d^{I I A}= \\
(8)-(14)\end{array}$ & $\begin{array}{c}\text { Độ } \\
\text { chênh } \\
\delta^{I N}= \\
(9)-(15)\end{array}$ \\
\hline (1) & (2) & (3) & (4) & (5) & (6) & (7) & (8) & (9) & (10) & (11) & (12) & (13) & (14) & (15) & (16) & (17) \\
\hline \multicolumn{17}{|c|}{ Ngày $21 / 12 / 2019$} \\
\hline 1 & 2293621 & 626316 & $7: 33: 42$ & 11.34 & 0.71 & 2.84 & -10.63 & -8.50 & -0.04 & -2.16 & 0.6 & 2.77 & -10.69 & -8.57 & 0.06 & 0.07 \\
\hline 2 & 293615 & 26309 & $7: 33: 47$ & 11.74 & 0.71 & 2.84 & -1 & -8.90 & -0 & & & 2.77 & 1.09 & -8.97 & 0.06 & 0.07 \\
\hline 3 & 193609 & 6301 & $7: 33:$ & & & 2.84 & & & & & & & & & & 0.07 \\
\hline 4 & 2293602 & \begin{tabular}{|l|l|}
626293 \\
\end{tabular} & $7: 33: 51$ & 12.04 & 0.71 & 2.84 & -11 & -9.20 & -0.04 & & 0.65 & 2.77 & -11.39 & -9.27 & 0.06 & 0.07 \\
\hline 5 & 293596 & 626285 & 7:33: & & & 2.84 & & -9.20 & & & & & & -9.27 & 0.06 & 0.07 \\
\hline 6 & 2293590 & 26277 & $7: 33: 57$ & 12.94 & 0.71 & 2.84 & -12.23 & -10.10 & -0.0 & -2 & 0.65 & 2.77 & -12.29 & -10.17 & 0.06 & 0.07 \\
\hline 7 & 293585 & 26269 & $7: 34: 00$ & 14.54 & 0.71 & 2.84 & -13.83 & 170 & -0.04 & & 0.65 & 2.78 & -13.89 & -11.77 & 0.06 & 0.06 \\
\hline 8 & 293579 & 626260 & $7: 34$ & 14.14 & & 2.84 & & & & & & 2.7 & 3.49 & 37 & 0.06 & 0.06 \\
\hline 9 & 2293574 & 626252 & $7: 34: 06$ & 14.84 & 0.71 & 2.84 & -14.13 & -12.00 & -0.04 & -2.16 & 0.6 & 2.78 & -14.19 & -12.07 & 0.06 & 0.06 \\
\hline & & & & & & & & & $\ldots$ & &.. & $\cdots$ & $\ldots$ & $\ldots$ & $\ldots$ & $\ldots$ \\
\hline 3401 & 288963 & 629601 & $23: 42$ & 17.43 & 0 & 3.07 & -16.49 & -14.36 & -0.06 & -2.1 & 0.96 & 3.02 & -16.47 & -14.41 & -0.02 & 0.05 \\
\hline 3402 & 2288969 & 629609 & $10: 23: 45$ & 17.33 & 0.9 & 3.07 & -16.39 & -14.26 & -0.06 & -2. & 0. & 3. & -16.37 & -14 & -0.02 & 0.05 \\
\hline 3403 & 2288975 & \begin{tabular}{|l|l|}
629617 \\
\end{tabular} & 0:23:48 & & 0.9 & 3.07 & -16.49 & -14.36 & -0.06 & -2 & 0 & 3. & -16.47 & -14.41 & -0.02 & 0.05 \\
\hline 3404 & 2288980 & 629625 & $23: 51$ & 17.43 & 0.94 & 3.07 & -16.49 & -14.36 & -0.06 & -2. & 0.96 & 3.02 & -16.47 & $\begin{array}{l}-14.41 \\
\end{array}$ & -0.02 & 0.05 \\
\hline 3405 & 2288986 & \begin{tabular}{|l|l|}
629634 \\
\end{tabular} & $10: 23: 54$ & 17.53 & 0.94 & 3.07 & -16.59 & -14.46 & -0.06 & -2.12 & 0.96 & 3.02 & -16.57 & -14.51 & -0.02 & 0.05 \\
\hline & & & & & $\ldots$ & & $\ldots$ & $\ldots$ & $\ldots$ & & & & $\ldots$ & $\ldots$ & $\ldots$ & $\ldots$ \\
\hline 6872 & 2296967 & 623854 & $: 30: 23$ & 7.68 & 0.6 & 2.80 & -7.01 & -4.8 & -0.02 & -2.21 & 0.57 & 2.77 & -7.10 & $\begin{array}{r}-4.91 \\
\end{array}$ & 0.10 & 0.03 \\
\hline 6873 & 2296973 & \begin{tabular}{|l|l|}
623863 \\
\end{tabular} & $: 30: 26$ & 7.49 & & 2.80 & -6.82 & -4.69 & -0.02 & -2.21 & 0.57 & 2.77 & -6.91 & $\begin{array}{l}-4.72 \\
\end{array}$ & 0.10 & 0.03 \\
\hline 6874 & 296978 & 3871 & & & & & & & & & & & & & 0.10 & 0.03 \\
\hline 6875 & 2296984 & \begin{tabular}{|l|l|}
623879 \\
\end{tabular} & $13: 30: 32$ & 6.03 & & 2.80 & $\begin{array}{l}5.36 \\
\end{array}$ & -3.23 & -0.02 & -2.21 & 0.57 & 2.77 & -5.45 & \begin{tabular}{|l|} 
\\
\end{tabular} & 0.10 & 0.03 \\
\hline 6876 & 2296989 & 623888 & 8:30:35 & 5.67 & & 2.80 & -5.00 & -2.87 & -0.02 & -2.21 & 0.57 & 2.77 & -5.09 & -2.90 & 0.10 & 0.03 \\
\hline 6877 & 2296995 & 623896 & & & & & & & & & & 2.77 & -5.00 & -2.81 & 0.10 & 0.03 \\
\hline 6878 & 2297000 & \begin{tabular}{|l|l|}
623907 \\
\end{tabular} & $13: 30: 41$ & 5.39 & 0.6 & 2.80 & -4.72 & -2.59 & -0.02 & -2.21 & 0.57 & 2.77 & -4.81 & -2.62 & 0.10 & 0.03 \\
\hline
\end{tabular}

\begin{tabular}{|c|c|c|c|c|c|c|c|c|c|c|c|c|c|c|c|c|}
\hline \multicolumn{17}{|c|}{ Ngày 22/12/2019 } \\
\hline 6879 & 2303182 & 619275 & $8: 06: 35$ & 9.45 & 0.5. & 2.68 & -8.90 & -6.77 & 0.02 & -2.29 & 0.46 & 2.77 & -9.00 & -6.69 & 0.09 & -0.09 \\
\hline 6880 & 2303345 & 619080 & $8: 06: 53$ & 7.02 & 0.5. & 2.68 & -6.47 & -4.34 & 0.02 & -2.30 & 0.45 & 2.77 & -6.57 & -4.25 & 0.10 & -0.09 \\
\hline 6881 & 2303336 & 619076 & $8: 07: 12$ & 7.51 & 0.5. & 2.68 & -6.96 & -4.83 & 0.02 & -2.30 & 0.45 & 2.77 & -7.05 & -4.73 & 0.10 & -0.09 \\
\hline 6882 & 2303326 & 619072 & $8: 07: 30$ & 7.44 & 0.5 & 2.68 & -6.89 & -4.76 & 0.02 & -2.30 & 0.45 & 2.77 & -6.98 & -4.66 & 0.10 & -0.09 \\
\hline 6883 & 2303317 & 619068 & $8: 07: 48$ & 7.86 & 0.5 & 2.68 & -7.31 & -5.18 & 0.02 & -2.30 & 0.45 & 2.77 & -7.40 & -5.08 & 0.10 & -0.09 \\
\hline 6884 & 2303308 & 619064 & $8: 07: 54$ & 8.75 & 0.5. & 2.68 & -8.20 & -6.07 & 0.02 & -2.30 & 0.45 & 2.77 & -8.29 & -5.97 & 0.10 & -0.09 \\
\hline 6885 & 2303299 & 619060 & $8: 08: 17$ & 9.93 & 0.5 & 2.68 & -9.38 & -7.25 & 0.02 & -2.30 & 0.45 & 2.78 & -9.47 & -7.15 & 0.10 & -0.10 \\
\hline 6886 & 2303290 & 619055 & $8: 08: 21$ & 10.36 & 0.5. & 2.68 & -9.81 & -7.68 & 0.02 & -2.30 & 0.45 & 2.78 & -9.90 & -7.58 & 0.10 & -0.10 \\
\hline 6887 & 2303281 & 619051 & $8: 08: 42$ & 10.70 & 0.5. & 2.68 & -10.15 & -8.02 & 0.02 & -2.30 & 0.45 & 2.78 & -10.24 & -7.92 & 0.10 & -0.10 \\
\hline$\ldots$ & $\ldots$ & $\ldots$ & $\ldots$ & $\ldots$ & $\ldots$ & $\ldots$ & $\ldots$ & $\ldots$ & $\ldots$ & $\ldots$ & $\ldots$ & $\ldots$ & $\ldots$ & $\ldots$ & $\ldots$ & $\ldots$ \\
\hline 9001 & 2300848 & 620948 & $15: 31: 03$ & 16.02 & 0.25 & 2.38 & -15.77 & -13.64 & 0.00 & -2.27 & 0.09 & 2.36 & -15.93 & -13.66 & 0.16 & 0.02 \\
\hline 9002 & 2300842 & 620940 & $15: 31: 06$ & 15.82 & 0.25 & 2.38 & -15.57 & -13.44 & 0.00 & -2.27 & 0.09 & 2.36 & -15.73 & -13.46 & 0.16 & 0.02 \\
\hline 9003 & 2300837 & 620932 & 15:31:09 & 15.72 & 0.25 & 2.38 & -15.47 & -13.34 & 0.00 & -2.27 & 0.09 & 2.36 & -15.63 & -13.36 & 0.16 & 0.02 \\
\hline 9004 & 2300831 & 620924 & $15: 31: 11$ & 14.42 & 0.25 & 2.38 & -14.17 & -12.04 & 0.00 & -2.27 & 0.09 & 2.36 & -14.33 & -12.06 & 0.16 & 0.02 \\
\hline 9005 & 2300825 & 620915 & $15: 31: 15$ & 15.52 & 0.25 & 2.38 & -15.27 & -13.14 & 0.00 & -2.27 & 0.09 & 2.36 & -15.43 & -13.16 & 0.16 & 0.02 \\
\hline$\ldots$ & $\ldots$ & $\ldots$ & $\ldots$ & $\ldots$ & $\ldots$ & $\ldots$ & $\ldots$ & $\ldots$ & $\ldots$ & $\ldots$ & $\ldots$ & $\ldots$ & $\ldots$ & $\ldots$ & $\ldots$ & $\ldots$ \\
\hline 11133 & 2293643 & 626250 & $17: 17: 39$ & 12.11 & 0.08 & 2.21 & -12.03 & -9.90 & -0.04 & -2.16 & -0.07 & 2.05 & -12.19 & -10.07 & 0.15 & 0.16 \\
\hline 11134 & 2293649 & 626258 & $17: 17: 41$ & 11.41 & 0.08 & 2.21 & -11.33 & -9.20 & -0.04 & -2.16 & -0.07 & 2.05 & -11.49 & -9.37 & 0.15 & 0.16 \\
\hline 11135 & 2293655 & 626266 & $17: 17: 45$ & 11.11 & 0.08 & 2.21 & -11.03 & -8.90 & -0.04 & -2.16 & -0.07 & 2.05 & -11.19 & -9.07 & 0.15 & 0.16 \\
\hline 11136 & 2293662 & 626274 & $17: 17: 48$ & 11.01 & 0.08 & 2.21 & -10.93 & -8.80 & -0.04 & -2.16 & -0.07 & 2.05 & -11.09 & -8.97 & 0.15 & 0.16 \\
\hline 11137 & 2293668 & 626281 & $17: 17: 51$ & 11.01 & 0.08 & 2.21 & -10.93 & -8.80 & -0.04 & -2.16 & -0.07 & 2.05 & -11.09 & -8.97 & 0.15 & 0.16 \\
\hline 11138 & 2293675 & 626289 & $17: 17: 53$ & 10.51 & 0.08 & 2.21 & -10.43 & -8.30 & -0.04 & -2.16 & -0.07 & 2.05 & -10.59 & -8.47 & 0.15 & 0.16 \\
\hline 11139 & 2293680 & 626298 & $17: 17: 57$ & 9.71 & 0.08 & 2.21 & -9.63 & -7.50 & -0.04 & -2.16 & -0.07 & 2.05 & -9.79 & -7.67 & 0.15 & 0.16 \\
\hline \multirow[t]{3}{*}{11140} & 2293685 & 626306 & $17: 18: 00$ & 6.81 & 0.08 & 2.21 & -6.73 & -4.60 & -0.04 & -2.16 & -0.08 & 2.05 & -6.89 & -4.77 & 0.16 & 0.16 \\
\hline & & & & & & & & & & & & & & $\Sigma=$ & 770.55 & 220.28 \\
\hline & & & & & & & & & & & & & & $\mathrm{m}=$ & \pm 0.041 & \pm 0.047 \\
\hline
\end{tabular}


Do MBTN sử dụng để quy chiếu các điểm đo độ sâu ĐHĐB theo số liệu của mô hình triều chênh so với MBTB là một hằng số (lấy theo số liệu trạm nghiệm triều Hòn Dấu, độ chênh $\mathrm{A} 0-\pi 0=2.13 \mathrm{~m}$ ), nên độ chính xác giữa hai dãy độ sâu quy chiếu dựa trên MBTN theo số liệu quan trắc mực nước tại trạm QTTT tạm thời ven bờ và dựa trên $\mathrm{MBTN}$ tại vị trí các điểm đo độ sâu ĐHĐB theo số liệu của mô hình triều cũng bằng $\pm 0.034 \mathrm{~m}$.

Bằng phương pháp tương tự, độ chính xác giữa độ sâu ĐHĐB quy chiếu dựa trên MBTB theo số liệu quan trắc mực nước tại trạm QTTT tạm thời ven bờ và dựa trên mô hình $\mathrm{MBT}$ BKV98 theo số liệu của mô hình triều đạt $\pm 0.041 \mathrm{~m}$, còn độ chính xác giữa độ sâu ĐHĐB quy chiếu dựa trên MBTN theo số liệu quan trắc mực nước tại trạm QTTT tạm thời ven bờ và dựa trên mô hình MBTNKV170 theo số liệu của mô hình triều đạt $\pm 0.047 \mathrm{~m}$.

Trên cơ sở kết quả đánh giá độ chính xác độ sâu ĐHĐB quy chiếu dựa trên MBTB theo số liệu quan trắc mực nước tại trạm QTTT tạm thời ven bờ và quy chiếu dựa trên các mô hình mặt biển (mô hình tính toán thủy triều, mô hình MBTBKV98 và mô hình MBTNKV170) ta thấy rằng hoàn toàn có thể sử dụng mô hình tính toán thủy triều MIKE21 FM để hiệu chỉnh thủy triều trong các trị đo sâu ĐHĐB phục vụ công tác thành lập bản đồ biển ở các dãy tỷ lệ trung bình và nhỏ.

\section{Kết luận}

Độ cao mực nước xác định từ mô hình tính toán thủy triều MIKE21 FM hoàn toàn có thể thay thế số liệu quan trắc mực nước tại trạm QTTT tạm thời ven bờ để quy chiếu các trị đo sâu ĐHĐB.

Từ kết quả tính toán thực nghiệm và đánh giá độ chính độ sâu quy chiếu dựa trên MBTB tại trạm QTTT tạm thời ven bờ và quy chiếu dựa trên các mô hình mặt biển (mô hinh tính toán thủy triều MIKE21 FM, mô hình MBTBKV98

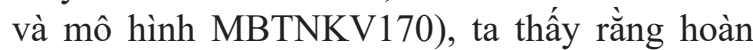
toàn có thể sử dụng các mô hình mặt biển để quy chiếu các trị đo sâu ĐHĐB phục vụ công tác thành lập bản đồ ĐHĐB và hải đồ ở các dãy tỷ lệ trung bình và nhỏ.

Phương pháp xây dựng MBTB dựa trên độ cao tại các biên lỏng để nội suy độ cao triều mô hình của Trung tâm Hải văn tuy đáp ứng được các nhiệm vụ của Tổng cục Biển và Hải đảo Việt Nam liên quan đến động lực biển, nhưng đối với công tác trắc địa, bản đồ vẫn còn nhiều hạn chế. Chúng tôi đã có kế hoạch phối hợp với Trung tâm Hải văn để giải quyết trọn vẹn bài toán quy chiếu các trị đo sâu ĐHĐB dựa trên các mô hình mặt biển phục vụ công tác đo đạc, thành lập bản đồ biển ở mọi dãy tỷ lệ. Các kết quả này sẽ được công bố trong các công trình tiếp theo. $\bigcirc$

\section{Tài liệu tham khảo}

[1]. Bộ Khoa học Công nghệ, (2015). TCVN 10337:2015. Tiêu chuẩn kỹ thuật Quốc gia về "Hải đồ vùng nước cảng biển và luồng hàng hải - Yêu cầu kỹ thuật cho hải đồ giấy - Ký hiệu”. Hà Nội.

[2]. Bộ Tài nguyên và Môi trường, (2007). Quyết định Ban hành quy định kỹ thuật thành lập bản đồ địa hình đáy biển tỷ lệ 1: 50 000. Số 03/2007/QĐ-BTNMT ngày 12 tháng 02 năm 2007.

[3]. Hà Minh Hòa, (2015). Nghiên cứu đánh giá các mặt chuẩn mực nước biển (mặt " 0 " độ sâu, trung bình và cao nhất) theo các phương pháp trắc địa, hải văn và kiến tạo hiện đại phục vụ xây dựng các công trình và quy hoạch đới bờ Việt Nam trong xu thế biến đổi khí hậu. Báo cáo tổng hợp kết quả Đề tài NCKH cấp Nhà nước. Mã số KC.09.19/11-15. Bộ Khoa học và Công nghệ.

[4]. Lương Thanh Thạch, Nguyễn An Định, Trần Văn Hải, (2020). Hoàn thiện mô hình mặt biển trung bình khu vực và mô hình mặt biển thấp nhất khu vực trên vùng biển Việt Nam. Tạp chí Khoa học Tài nguyên và Môi trường, số 29, tháng $3 / 2020$.

[5]. Lương Thanh Thạch, Nguyễn An Định, Nguyễn Thị Hồng, Trần Văn Hải, (2020). Quy 
chiếu trị đo sâu địa hình đáy biển dựa trên các mô hình mặt biển. Tạp chí Khoa học Đo đạc và Bản đồ, số 43, tháng 3/2020.

[6]. Phạm Văn Huấn, (2002). Động lực học biển, Phần 3- Thủy triều. NXB Đại học Quốc gia, Hà Nội.

[7]. De Jong C.D., Lachapelle G., Skone S., Elema I.A., (2003). Hydrography (Second edition 2003). UP Blue Print is an imprint of: Delft University Press. P.O. Box 98, 2600 MG Delft, The Netherlands.
[8]. Wouter J. M. K., Jim E. F., and Ross A. W., (2019). Technical note: Inherent benchmark or not? Comparing Nash-Sutcliffe and Kling-Gupta efficiency scores. Hydrology Earth System Scienses, 23, 4323-4331, 2019. https://doi.org/10.5194/hess-23-4323-2019.

[9].

https://manuals.mikepoweredbydhi.help/201 7/MIKE 21.htm. O

\section{Summary}

\section{Referring seabed topographic depths based on tidal calculation model and sea surface models}

Hong Thi Nguyen, Vietnam Maritime University

Trang Thanh Nguyen, Centre for oceanography

Thach Thanh Luong, Hanoi University of Natural Resources and Environment

Dinh An Nguyen, Survey and Aerial mapping onemember Co., Ltd.

Hai Van Tran, Survey Enterprise, Survey and Aerial mapping onemember Co,. Ltd.

\section{Mong Van Do, Vietnam's Naval Hydrograhic and Ocenographic Department}

This article presents the method of using tidal calculation model MIKE21 FD to adjust tides in referring seabed topographic depth based on regional mean sea surface model (MBTBKV98) and regional lowest sea surface model (MBTNKV170), which is published in document [4]. The accuracy assessing results of the difference between referred depths based on the water level observations at temporary coastal tidal gauge station and tidal calculation model in Hai Phong sea reached $0.034 \mathrm{~m}$; difference between referred depths based on water level observations at tide gauge station and MBTBKV98 model, combined with model tide data reached $0.041 \mathrm{~m}$, while the difference between referred depth based on lowest sea surface at tide gauge station and model MBTNKV170 combined with model tide data reached $0.047 \mathrm{~m}$. This shows that using the MIKE21 FD tidal calculation model to adjust the tide in referring seabed topographic depth measurements based on the sea surface models fully meets the requirements of creating seabed topographic maps and sea charts at medium and smaller scale ranges in Vietnamese waters. $O$ 